\title{
Citizen-Based Air Quality Monitoring: The Impact on Individual Citizen Scientists and How to Leverage the Benefits to Affect Whole Regions
}

\author{
Teresa Schaefer, Barbara Kieslinger and Claudia Magdalena Fabian
}

\begin{abstract}
Air pollution is a serious problem that is causing increasing concern among European citizens. It is responsible for more than 400,000 premature deaths in Europe each year and considerably damages human health, agriculture, and the natural environment. Despite these facts, the readiness and power of citizens to take actions is limited. To address this challenge, the citizen science project CAPTOR was launched in 2016. Using low-cost measurement devices, citizens in three European testbeds supported the monitoring of tropospheric ozone. This paper presents the results from 53 interviews with involved residents and shows that the active involvement of individuals in a complex process such as measuring tropospheric ozone can have important impacts on their knowledge and attitudes. In an attempt to expand the benefits of low-cost air quality sensors from an individual to a regional level, certain preconditions are key. Strong support in assuring data quality, visibility of the collected data in online and offline media, broad dissemination of results, and intensified communication with political decision-makers are needed.
\end{abstract}

Keywords: Citizen science; air quality monitoring; impact; air sensing

\section{Introduction}

Air pollution is a global danger leading to large impacts on human health and worldwide ecosystems. "Ninety-five percent of the world's population lives in areas exceeding the limits defined by the WHO Guideline for healthy air" (HEI 2018, p.3). Emissions have increased in many areas worldwide over the last years and as far as Europe is concerned, air quality remains poor in many areas. Air pollution has been identified as the single largest environmental health risk in Europe (HEI 2018), and long-term exposure is responsible for more than 400,000 premature deaths (EEA 2018). Air pollution has significant impacts on the health of the population, vegetation, and economy, cutting lives short, increasing medical costs, and reducing productivity through lost working days.

To respond to this major public health threat, in 2016 the WHO Member States agreed on a road map for "an enhanced global response to the adverse health effects of air pollution." Among the main elements of the agenda are the monitoring and reporting of air pollution and the establishment of enhanced systems, structures, and processes for monitoring and reporting health trends associated with air pollution and its sources (WHO 2016). Several citizen science projects contribute to these objectives. Low-cost sensors are deployed to measure and

Centre for Social Innovation, AT

Corresponding author: Teresa Schaefer (schaefer@zsi.at) map air quality together with citizens, thereby supporting well-informed actions and bringing the topic to a wider audience, including policy makers.

Despite some flagship projects around the world that show the great potential of low-cost citizen science sensing (Conrad and Hilchey 2011, Van Brussel and Huyse 2018), a main challenge for a large majority of projects is developing accurate measurement devices and assuring data quality (Williams et al. 2018). Additionally, relatively few studies bring evidence for the social and socio-ecological impact of citizen science air monitoring projects in terms of effects on the lives of individuals and on their communities and regions (Groulx et al. 2017).

Especially rare are citizen sensing projects related to tropospheric ozone $\left(\mathrm{O}_{3}\right)$. Ozone is frequently considered a forgotten pollutant, in the sense that it is formed in rural areas through chemical reactions from precursor gases emitted mainly in urban environments. To address this challenge, CAPTOR (Collective Awareness Platform for Tropospheric Ozone Pollution) - a research project funded under the European Horizon 2020 Programme - was launched. In three testbeds-Italy, Austria, and Spain-46 low-cost ozone measurement devices, the so-called CAPTORs, were installed outside citizens' private houses (hosts) to collect data on ozone pollution in the summer months of 2017 and 2018. The project aimed to 1) advance existing knowledge on the usage of low-cost sensors for ozone measurement and 2) learn about the impact of the involvement of citizens as sensor hosts. At the end of each 
measurement period, interviews were conducted with CAPTOR hosts to learn how much their involvement in the project impacted them as individuals and impacted their neighbourhoods. Analyses of these interviews, together with onsite observations from the research team, are presented in this paper. Insights on the technical aspects of the low-cost ozone measurement are presented in Ripoll et al. (2019) and Barcelo-Ordinas et al. (2018).

\section{Present Research \\ Citizen science air sensing}

Currently, in most developed countries, air pollution is monitored by networks of stations equipped with highlevel reference instrumentation, maintained by government agencies and producing high-quality data necessary for regulatory applications (EEA 2018, Williams et al. 2018). The high costs of the official monitoring stations, both in terms of purchasing and maintenance, and the recent advances in mobile sensors and software applications, have raised an increased interest in setting up citizen-based sensing networks that complement the current air quality networks and increase spatial and temporal density (Macdonell et al. 2013, Castell et al. 2013). Air quality monitoring is rapidly changing with miniaturized, lower-cost air sensors that enable cities, community groups, businesses, and consumers to monitor local air quality conditions, raising awareness of air pollution problems and potentially supporting decision making. Different technologies are falling within this class, reaching from completely passive sensors that cost only a few euros to more complex and more expensive micro-electromechanical devices that use the same analytical principles as reference instruments (WMO 2018). Low-cost air sensors spread across a wide range of devices produce a variable quality of measurements. Therefore, their potential is still tempered by concerns about quality (Muller et al. 2015, Castell et al. 2017). Currently, low-cost air sensors are used mostly for supplemental monitoring (supplementing official reference data). They also contribute to community near-source monitoring, public education, and the detection of contaminated places (Williams et al. 2018). The usage of low-cost sensors for decision support is less frequent, because policy decisions have the strictest performance requirements for precision, accuracy, completeness, and detection limit of data (Williams et al. 2018). Another barrier relates to costs: The price for sensors has been considerably reduced within the last years, but the maintenance of sensor networks and the post-processing of collected data is labour-intensive and likely to exceed the costs of the sensors themselves (Kumar et al. 2015).

The US Environmental Protection Agency (EPA) has created the Air Sensor Toolbox (https://www.epa.gov/ air-sensor-toolbox) as a central place of guidance and information about air sensors and the conducting of citizen science projects to measure air quality. In 2018, the European Citizen Science Organisation (ECSA) established the Working Group on Air Quality, which aims to foster exchange amongst practitioners and researchers in the field. Following the current trend towards low-cost air quality monitoring, a number of scattered projects in
Europe now involve citizens in air quality monitoring. Most prevalent are projects related to the measurement of nitrogen dioxide $\left(\mathrm{NO}_{2}\right)$, which is one of the major pollutants found in cities and originates from the burning of fossil fuels and car emissions. These projects mostly use Palmes passive diffusion tubes to map $\mathrm{NO}_{2}$ concentrations (Palmes et al. 1976), which reach accurate data quality despite the low price of devices (Van Brussel and Huyse 2018). Initiatives in the Netherlands, UK, and Italy helped to prove $\mathrm{NO}_{2}$ exceedances and raised awareness amongst citizens for their exposure to this pollutant. The high spatial density of sensors also supported the identification of areas with high pollution and those less affected. The results led to the development of measures to avoid exposure to this pollutant. Furthermore, the European initiatives impacted the participants' knowledge, self-efficacy, and attitudes towards $\mathrm{NO}_{2}$ pollution; they resulted in changed or adjusted behaviour of the involved citizens towards measures to exposure and contribution to air pollution, led to a higher sense of community, stimulated discussions with policy makers, and influenced political decisions in the involved regions (Francis and Stockwell 2014, Hsu et al. 2017, Kloetzer et al. 2017, Zannella 2017, Van Brussel and Huyse 2018, Haklay and Eleta 2019). Other projects, such as Luftdaten (https:// luftdaten.info/), HackAir (https://platform.hackair.eu/), and senseBox (https://sensebox.de/) experiment with self-made sensor kits and data platforms to measure particulate matter (PM), a mixture of solid particles and liquids found in the air which are either emitted directly from a source, like a construction site, or are the result of chemical reactions of other pollutants, such as $\mathrm{NO}_{2}$. The collected data on PM from such low-cost sensors are accessible on web platforms and mobile applications. As there are no processes yet to guarantee data quality adequate for regulatory actions regarding PM, the main aim of the above mentioned projects is to inform, raise awareness, and educate, e.g., by integrating air sensing as a topic to current school curricula. In the Citi-Sense project, for example, nodes monitoring $\mathrm{NO}_{2}$ were installed close to kindergartens in Oslo with the aim to test data quality. A focus group revealed interest of parents and teachers in the local air quality information, but at the same time showed that uncertainty on data quality still hampers further action (Castell et al. 2018).

\section{Tropospheric ozone and its measurement}

Tropospheric ozone is a secondary pollutant that is formed from complex chemical reactions of nitrogen oxides (NOX) and volatile organic compounds (VOCs), carbon monoxide $(\mathrm{CO})$, or methane $\left(\mathrm{CH}_{4}\right)$, in the presence of sunlight, resulting in high ozone episodes especially in summer. It is an air pollutant with significant impacts on health, ecosystems, crops, and forests, as well as climate (EEA 2018). Ozone dynamics are strongly influenced by air mass movements from regions where precursors are emitted (typically, urban areas) to regions where ozone exposures occur (typically, suburban and rural areas). The lower population density in rural areas is reflected in a lower number of reference air quality monitoring stations; 
this limited information on ozone pollutants may result in low awareness of the pollutant as well as low political and environmental pressure for action by rural residents. Besides, rural populations have limited influence on the emissions, which degrade the air they breathe.

Only a small number of projects measure tropospheric ozone using low-cost devices. CairClip hosted five ozone sensors in North America and concluded that their sensor provided a consistent measurement response to that of reference monitors (Duvall et al. 2016). The Village Green project (https://www.epa.gov/air-research/village-green-project) integrated ozone measurement devices into its stations, monitoring several pollutants in real-time and making the data available online and by smartphone, with the aim to raise awareness for community-based air quality monitoring systems. In the $\mathrm{GO}_{3}$ Project (http://go3project.com/network2/index.php/ pages/global-ozone-project), schools were equipped with high-cost and high-quality measurement devices to collect ozone data and build a global ozone database. In Europe, the CITI-SENSE project (http://www.citi-sense. $\mathrm{eu} /$ ) trialled low-cost measurement devices in Edinburgh and Oslo intending to learn more about the reliability and accuracy of the devices. None of these projects reported on their impact on citizens and communities involved or analysed how the sensor hosts interacted with the devices and acted as promoters of the project.

\section{Understanding the impact of citizen science projects in environmental monitoring}

Taking a look at the impact of citizen science in environmental monitoring at large, there is evidence for its potential. Citizen science has emerged as a promising option for tackling serious challenges in the fields of conservation biology, natural resource management, and environmental protection (McKinley et al. 2017). The most common impact on individual participants discussed in the literature is learning new content knowledge and gaining science literacy (Stepenuck and Green 2015). A metaanalysis of learning effects showed that gaining content knowledge - reflecting the topic of focus - was by far the most reported type of learning in citizen science projects (Stepenuck and Green 2015). Another meta-analysis on climate change and citizen science showed the outcome of new knowledge being the most important impact of citizen science in climate change (Groulx et al. 2017). In contrast, according to this analysis, relatively few studies refer to outcomes beyond new knowledge gains, like a sense of empowerment, a feeling of contributing to science, or insight into one's values and interests (Groulx et al. 2017). The authors state that these results might be due partly to a notable gap in documented evidence.

Next to increase in knowledge, changes in attitudes and behaviour are a consequence of citizen engagement; for instance, many citizens seem to care more about their residential environment and are also more responsive as they learn how to measure and prove contamination (Zerbe and Wilderman 2010). Participants' involvement influences their ecological perceptions and sense of place (Evans et al. 2005, Ballard et al. 2017), as it improves their understanding of the connections existing between science, place, ecosystem, and the impacts of one's actions on the environment. Also, changing attitude towards more environmentally sustainable resource management could be observed amongst environmental citizen scientists (Danielsen et al. 2005). Individuals diffuse their acquired skills and knowledge to peers through social networks (Overdevest et al. 2004, Johnson et al. 2014) and feel more confident to express their ideas to natural resource managers and figures of authority (Cornwell and Campbell 2012, Ballard et al. 2017), thus increasing their political participation (Overdevest et al. 2004). In part, this is attributed to citizens recognizing the influence of scientific data (Cornwell and Campbell 2012).

So citizen science in environmental monitoring can increase the potential for acquiring new knowledge while creating information that goes into policy formulation, planning, and management activities at various levels of government.

\section{Driving questions of research}

This research set out to bring insights into how far the measurement of tropospheric ozone using low-cost sensors can influence the involved sensor hosts as well as their regions. It aimed to better understand the hosts' activities in the project, as well as their motivations for involvement. As ozone is a complex pollutant and the usage of low-cost sensors to measure it is still a technological challenge concerning data quality, the results discussed in the following sections can enrich other environmental monitoring projects working within the same complexity.

\section{Methods \\ Design of the measurement campaigns}

In CAPTOR two types of measurement devices were used: Metal oxide and electrochemical sensing devices with Arduino or Raspberry-Pi. Sensor validation and calibration were carried out at regulatory-grade air quality monitoring stations in each of the testbeds. Direct contacts were established with local air quality monitoring network representatives, and permission to install the nodes at selected stations was requested and granted. Sensing devices were calibrated at the local regulatory stations for periods of at least three weeks prior to and after every sampling campaign. The sensing devices were calibrated in a twostep procedure; the nodes were initially calibrated in an urban environment and then subsequently at an air quality monitoring station located close to the actual area of deployment. This proved to be a highly successful enrichment to the study design, as it enhanced the quality of the calibrations and resulted in increased scientific credibility of the project's results (Ripoll et al. 2019). Measurement devices were installed in three testbeds where ozone levels were especially high. In Spain, the testbed area Plana de Vic is strongly affected by ozone due to the emissions from the area of Barcelona; in northern Italy, ozone levels are amongst the most critical in Europe and the industrial areas in Pianura Panda are big producers of ozone precursors. In Austria, the testbed regions suffer high ozone levels due to emissions from big cities such as Vienna and 
Graz as well as cross-border from Hungary (see testbed areas in Figure 1).

Citizens were approached by three Non-Governmental Organisations (NGOs) from the participating countries (Legambiente in Italy, Ecologistas in Spain, and G2000 in Austria) and invited to voluntarily participate in the project. Their task was to provide the space for CAPTOR devices outside their homes (e.g., balcony or garden). The devices themselves were installed by project team members. CAPTOR hosts were provided with background information on ozone in informal conversations with the project team and via the CAPTOR project website, but consuming this information was voluntary. When technical problems occurred with the measurement devices, the project team provided support. The results from the measurement devices were presented and visualised on an online platform that was developed specifically for that purpose (www.captor-air.org). CAPTOR hosts were not involved in any calibration of data or the initial construction of the measurement devices. They were informed from the very beginning that CAPTOR was a research project that aimed to learn how to optimize the quality of data from low-cost measurement devices and that low-cost measurement devices were not yet fully reliable.

The three testbeds were embedded in different contextual settings (Figure 2). Spain was involved in the distribution of CAPTOR measurement devices to citizen hosts over three years, with the first year mostly devoted to conducting technical tests. In Italy and Austria, the testbeds were implemented over two years. Italian and Spanish testbed hosts were embedded in a community of environmental activists, while Austrian participants were a mix of interested citizens and municipalities. Spain focused on a small geographical area in Catalonia with many devices and a clear source of pollutants, namely the city of Barcelona. Italy and Austria had bigger testbed areas with devices dispersed in regions where the source of pollutants was not as obvious.

\section{Participants}

In Spain, the same 20 locations hosted ozone measurement devices in 2017 and 2018. Eighteen were private households, one was a municipality, and one CAPTOR was deployed on a guild's house hosting various companies. In Austria, the measuring devices were allotted to citizens' private homes as well as public places in the affected areas. Six devices were provided to private homes and six were installed at public places, with six active in 2017 and 12 in 2018. In Italy, 14 ozone measurement devices were distributed to private households in 2017 and 2018, where 11 of the households took part twice.

In Spain, interviews were conducted with 13 hosts (9 male, 4 female) in 2017 and 12 hosts ( 9 male, 3 female) in 2018. In Austria, four hosts ( 3 male, 1 female) were interviewed in 2017 and nine hosts (4 male, 5 female) were interviewed in 2018. In Italy, six hosts (5 male, 1 female) were interviewed in 2017 and nine ( 5 male, 4 female) in 2018. Prior to their engagement in the project, the perceived knowledge of ozone was generally low amongst participants in all three testbeds, which was determined by a pre-participation questionnaire.

An overview of devices, interviewees, and their sociodemographic background is presented in Tables $\mathbf{1}$ and $\mathbf{2}$. Interview questions can be found in the supplemental file.

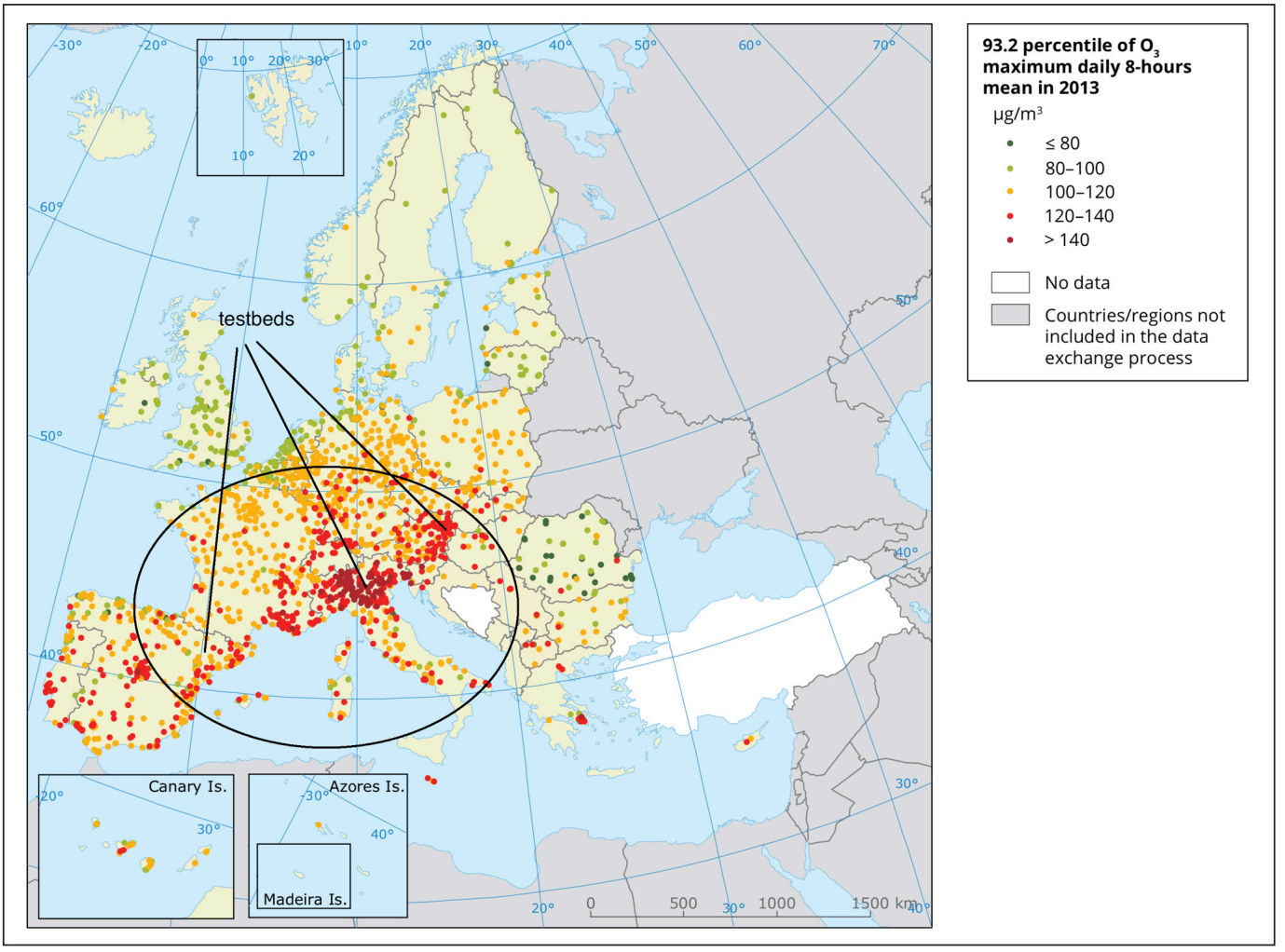

Figure 1: The three testbed areas and their $\mathrm{O}_{3}$ concentrations (EEA 2015). 


\section{Method of analysis}

All interviewees were approached by team members via e-mail and phone and participated voluntarily. In total 36 interviewees participated, of which 17 were interviewed twice (once in 2017 and once 2018). Interview guidelines were developed first in English and then translated to German, Italian, Catalan, and Spanish. The questions covered the interviewees' activities as hosts, the encountered problems, previous knowledge and experiences with ozone, the motivational drivers for participation, the perceived personal effects of participation, and the project's effects for the whole region. The interviews were conducted in the mother tongue of interviewees, tape-recorded, tran- scribed, and translated to English. The English translations were transferred to a content coding tool and represented the basis for the qualitative content-coding as proposed by Mayring (2010).

Two researchers coded the translated interviews independently from each other, using the initial questions as the overarching coding structure and creating sub-codes for each of the questions. These sub-codes were created based on the technique of summarisation in an inductive procedure by reducing, paraphrasing, and generalising relevant text passages using the content analysing tool MAXQDA (www.maxqda.com). Only those respective subcodes that both researchers agreed upon were retained.

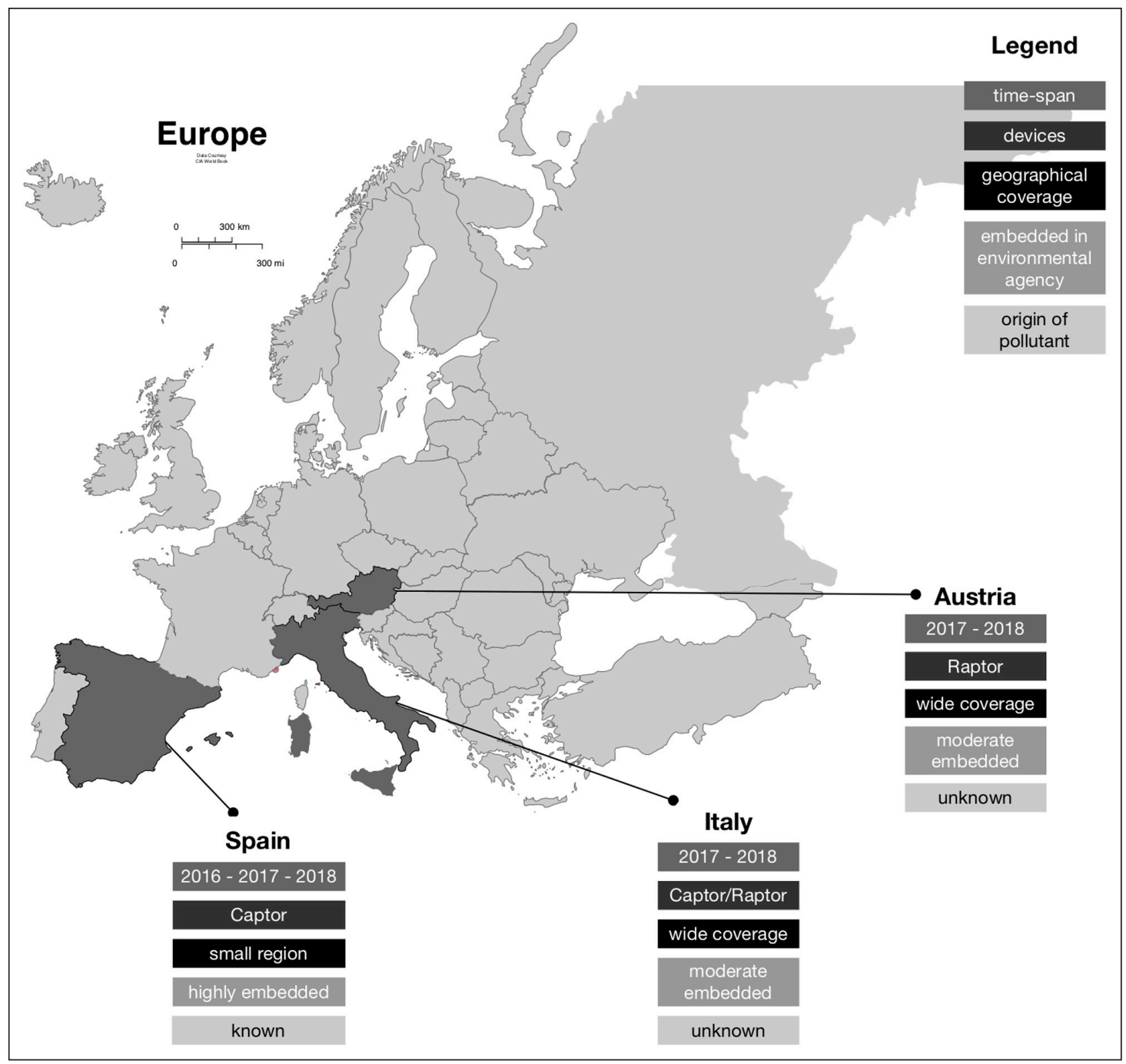

Figure 2: Different contextual settings in the three testbed regions.

Table 1: Number of devices and interviewees.

\begin{tabular}{lrrrrrr} 
& \multicolumn{2}{c}{ Spain } & \multicolumn{2}{c}{ Austria } & \multicolumn{2}{c}{ Italy } \\
\cline { 2 - 7 } & $\mathbf{2 0 1 7}$ & $\mathbf{2 0 1 8}$ & $\mathbf{2 0 1 7}$ & $\mathbf{2 0 1 8}$ & $\mathbf{2 0 1 7}$ & $\mathbf{2 0 1 8}$ \\
\hline No. Volunteer devices & 20 & 20 & 12 & 12 & 14 & 14 \\
No. Reference devices & 6 & 6 & 3 & 3 & 6 & 6 \\
No. Interviewees male & 9 & 9 & 3 & 4 & 5 & 5 \\
No. Interviewees female & 4 & 3 & 1 & 5 & 1 & 4
\end{tabular}


Table 2: Socio-demographic profiles of interviewees. When observing total note that some hosts were interviewed twice, in both 2017 and 2018.

\begin{tabular}{|c|c|c|c|c|}
\hline & Age Group & Male & Female & Profession \\
\hline \multirow[t]{8}{*}{ Spain } & $26-35$ & 1 & & Teacher \\
\hline & $26-35$ & & 1 & Homemaker \\
\hline & $36-45$ & 5 & & 3 farmers, 2 environmental scientists \\
\hline & $36-45$ & & 2 & Cinematographic producer, university professor \\
\hline & $46-55$ & 2 & & Owner catering company, plumber \\
\hline & $46-55$ & & 0 & \\
\hline & $56+$ & 3 & & 2 retired persons, university professor \\
\hline & $56+$ & & 2 & Retired person, teacher \\
\hline \multirow[t]{8}{*}{ Austria } & $26-35$ & 0 & & \\
\hline & $26-35$ & & 0 & \\
\hline & $36-45$ & 1 & & Head of department (local authority) \\
\hline & $36-45$ & & 3 & 2 project managers (NGOs), head of department (museum) \\
\hline & $46-55$ & 1 & & Coach and entrepreneur \\
\hline & $46-55$ & & 1 & Head of department (local authority) \\
\hline & $56+$ & 2 & & 2 retired persons \\
\hline & $56+$ & & 1 & Organic farmer \\
\hline \multirow[t]{9}{*}{ Italy } & $26-35$ & 2 & & Laboratory technician, research fellow \\
\hline & $26-35$ & & 0 & \\
\hline & $36-45$ & 1 & & Salesman \\
\hline & $36-45$ & & 2 & Teacher, homemaker \\
\hline & $46-55$ & 1 & & Teacher \\
\hline & $46-55$ & & 1 & Freelance \\
\hline & $56+$ & 2 & & Retired teacher, manager \\
\hline & $56+$ & & 2 & Farmer, retired person \\
\hline & TOTAL & 21 & 15 & \\
\hline
\end{tabular}

As participants were guaranteed anonymity, each person was assigned a unique code. Informed consent was obtained prior to the interviews in the mother tongue of interviewees.

\section{Results and Discussion}

\section{Motivation to participate}

Coding the 53 interviews with CAPTOR hosts revealed four main drivers of participation in the citizen science project.

Participation was driven mainly by an interest in local air pollution data, which in essence answers the question: How good is the air that I breathe? The project was expected to fulfil this very personal interest in environmental pollution at participants' homes and to provide insights on how to protect oneself and one's family from it.

"We live a bit outside the village. And there is an industrial company not too far from where we live and the wind comes from that direction and we can smell some type of contamination. So we wanted to know how we are in terms of air quality. Although we do not know if the company influences the ozone level or not, still, it was interesting to know our air quality. And in general, ozone is very high in the area of Ozona so it was good for me to know." (Spain, private, female, 2$)^{1}$

Secondly, hosts were driven by the will to support a useful research project. They were happy to provide a place for the measurement device so that researchers could collect the data they needed, trusting them to take further action, e.g., informing politicians and media if required so.

"Honestly, it is a very simple way of having the feeling that you've done something good. You let the device be installed in your garden and hope that somebody else can make something useful with the data." (Austria, private female, 1) 
Thirdly, hosts wanted to support the general aspiration to raise awareness on the problem of air pollution. In the interviews, a motivational driver to reach out to the local population and towards society, in general, was identified: To wake up, stimulate discussion, and enrich the work of awareness raising that NGOs are doing since years.

"My motivation was that society has the knowledge and has empirical data about pollution. So that people do not only have the information that there is low or high pollution, but that we have quantitative data. And if I can collaborate in this I am happy to help as much as I can." (Spain, private, male, 10)

Finally, some hosts were very interested in the technical aspects, e.g., the way that the sensors were built and how they complemented data from personal weather stations.

"I thought about constructing such a measurement device myself. And that's why I would have participated in any projected related to that - research or not." (Austria, private, male, 2)

The "neutral" aspect of the project, in the sense that the data were handled by independent researchers and the activities were not driven or influenced by any political party, was a strong motivational factor for participants. It gave the project high credibility across the participants.

\section{The hosts' behaviour}

The motivation to participate in the project also influenced the way that hosts interacted with the data from their measurement devices. Those who said that they were interested in the local ozone data accessed the data regularly, and also compared them with other data in their region and country (data from other CAPTORs or official measurement stations), to understand differences between measurement points. Those hosts who mainly wanted to support the relevant project work said that they accessed the data rarely - often at the beginning to see if the sensors were functioning properly - or when the temperature was high, and ozone was expected to be high.

"I think that it is very concrete when you have the device in your garden and you can look up your personal measurement data. In contrast to just talking about it and saying 'Ah it is hot today, we probably have too high ozone values today,' we have concrete measurement data now and see that ozone is in the red zone [above the limit values]." (Austria, private, female, 2)

The access point to the data for most hosts was the captorAIR website (http://captorair.org); only the technically interested hosts downloaded the raw data using the QR code on the measurement devices. They did so without having any specific training in data analysis by the project team.

The public hosts in Austria did not observe their data regularly but expected the project to deliver a final report that summarized the results of their measurement devices and compared the results with other regions. The private hosts also were interested in a final report, but in an easyto-read format containing the most important findings and outcomes.

Regardless of the initial motivation of participation or the frequency of interaction with the data, nearly all hosts talked about the project with others or disseminated project insights actively in their channels. Hosts said that just the fact of having the device in the garden made them talk about the project with friends and family, or brought the topic actively to the village council or their environmental organisations.

"In the second year, I was also telling my neighbours about the ozone level as they were interested and also asked me about it. I also sent the link to the project data to my contacts, like family and friends." (Spain, private, female, 7)

Of the three public administrations involved, two actively disseminated the project within their networks and also volunteered to discuss the topic in fora related to air quality monitoring or exchanged experiences with other public authorities. The third public administration did not communicate the topic further, but this was due to the interviewee's general perception that ozone is too complex to communicate and $\mathrm{CO}_{2}$ (carbon dioxide) or PM are more important pollutants to be addressed.

"I think that $\mathrm{CO}_{2}$ is the most important problem from a global point of view, and particulate matter the most important pollutant from a regional perspective. Does it make sense to also look at NOX and ozone? From an ecological point, yes, but we overburden the general public and politicians. They think they are not allowed to do anything anymore." (Austria, public, male, 1)

Considering data quality, we learned that participants expected a certain level of data accuracy compared to the reference stations, to avoid ridiculing themselves when becoming promoters of the topic. Data are expected to show values close to those of reference stations with a certain acceptable deviation. Hosts informed themselves about the quality of their data from comparing other stations or reading the project reports for each measurement device, summarising its performance at the end of a measurement campaign. In Spain, for instance, the low-cost devices were not able to measure the highest values of ozone pollution, thus their highest peaks were less extreme than those from the reference stations. A deviation in this direction was by hosts perceived as more acceptable than on the contrary direction.

\section{Impact on individual participants}

Clear similarities can be found across the three testbeds concerning impact on individual hosts. In all three countries, the qualitative data confirm that the most widespread impact was an increased knowledge on the topic of 
tropospheric ozone amongst the participants. Interviewees in all three countries mentioned that they learned about the existence and sources of ozone. Some of them became aware of it again, as especially in Austria there was quite intense communication about ozone in the media in the 1980s. Citizens learned how to protect themselves from the pollutant, for example by avoiding outdoor sports during hot peak times in summer.

For some, the most important personal benefit was learning about the range of ozone that is considered high and its potential negative effects on health.

\section{"Surely all of this allowed me and stimulated me to deepen my knowledge on the topic and to evalu- ate my actions related to their effect and for what concerned my health and that of my family." (Italy, private, male, 3)}

Next to this expected impact, which has been identified in previous studies (e.g., Stepenuck and Green 2015), the interview analysis revealed the following traces of impact that go beyond learning. As a consequence of their participation in the project, hosts reported on some feelings and capacities that show signs of empowerment. There is a reported feeling of being recognised as an expert and being able to talk to others in this capacity. The device and especially the local data helped to raise awareness of other citizens, as one could refer to some concrete values from the region. The local devices helped to bring in data that have more relevance than those from official measurement stations during presentations.

"It helped me to inform people in my surroundings and give them an instrument to become more environmentally aware. It served me to raise awareness of others. In some cases, beyond family and friends, as I facilitated some contacts with other groups, journalists, who had not touched upon this subject. Indirectly, I contributed to some communication that the media took on the topic and supported the campaign." (Spain, private, male, 12)

In addition, participants learned to access, observe, and understand the very local ozone data.

"I have observed that on Thursdays and Fridays, towards the end of the week, the concentration of ozone is higher in the area due to the movement in Barcelona. On the weekend the air is cleaner, also after the weekend, on Monday and Tuesday. And on Wednesday, Thursday the contamination gets higher again in the area. The highest concentrations come on Wednesday and Thursdays." (Spain, private, male, 8)

In most cases, however, knowing about the ozone concentration in the region and its health consequences did not result in changes in lifestyles. Interviewees stated that they either already try to avoid air pollution and live in an environmentally friendly way or that their behaviour is not likely to impact ozone pollution as the origins of this pollutant are elsewhere. Only very few participants in each testbed started to reflect on their lifestyles and how they can be changed to reduce pollution or to avoid being exposed to ozone.

"I was surprised to see how many times the data overrun the threshold, personally I think I will engage more and more to pollute the air the less that I can, to have less primary pollutants that can react with the ozone." (Italy, private, female, 7)

Finally, at a personal level of individual hosts, the interviews revealed a tendency to take political action without being specifically associated with any political party.

"The municipal council is always very busy, but important things are left undone. I rather stay out of this, as it is frustrating. I prefer to do projects. There I have the contact, some people are interested to do something. And even it doesn't have any political influence, we change things on an individual level." (Austria, private, male, 3)

\section{Regional impact}

If we take a closer look at the regional impact, differences in the testbed activities and the local contexts led to different impact. In Spain, the biggest impact was the raised awareness as a large majority of interviewees stated that the project considerably helped to raise awareness for ozone in the whole valley.

"In the region, there has been a lot of change. Before CAPTOR nobody talked about ozone and since CAPTOR was set up and information was published in social media there is nobody who would not know about ozone. Two years ago nobody knew about ozone and now everyone knows. Via flyers, conferences, information and dissemination activities, a lot of awareness-raising has taken place. The topic has gained a lot of attention. A lot has happened." (Spain, private, male, 8)

The dissemination activities mentioned in the statement above led to an increasing interest in the topic and finally its uptake in local television. Ozone was not only covered by the local television, but the municipality also installed a public screen, where air quality data including ozone are shown. For a representative from the municipality, this increased transparency of ozone data towards the public is an important achievement of CAPTOR.

"CAPTOR offered a way to get data that is actually from the very municipality, while the official data stations are a bit further away. The data is open, everyone can access it and consult it and this helps to achieve the objective of the municipality of transparency." (Spain, public, male, 6)

In Austria, hosts talked more about the "potential impacts" than the ones experienced during the measuring campaigns. The ozone measurement devices are understood 
as a good way to raise awareness of citizens about high ozone pollution. Hosts in Austria recommended the CAPTOR team to install even more devices in public places and to make the data visible there. Devices in public places in Hartberg and Weiz generated the most positive feedback. The devices were not very visible as such, but in these two locations, exhibitions were installed close to the devices, which were perceived as a good way to inform people about ozone, its effects on health, and where it comes from. In Austria, hosts expressed the feeling that the communication about ozone was much more intense and transparent some years ago and that now it has become a "forgotten pollutant." It does not appear in the media anymore and if there is any communication of data from the official measurement stations, it is not noticed by the hosts.

"I observe in the last years that the values are not presented to the general public anymore. You don't hear and see anything ... at least this is my impression when I look at the news on TV, the weather forecast or the Teletext. I miss that. I cannot imagine that everything is so great from one year to the other. Either it is swept under the carpet or we learned to live with certain values." (Austria, private, female, 3)

Contrary to Spain and Austria, the Italian hosts did not talk about any concrete regional impacts of CAPTOR.
As a summary, Table 3 shows the different contextual settings and outcomes.

\section{Implications and Conclusion}

This analysis of how individual participants are influenced by their involvement in a citizen science project on ozone measurement reveals clear parallels across the different cases studied in CAPTOR. On an individual level, the citizen science approach - the possibility of citizens to be hosts of low-cost ozone measurement devices - most importantly increased the hosts' knowledge about and awareness of ozone. It gave them the feeling of becoming experts in this area and being able to talk with others about it, which many hosts did. It also affected the habits of certain hosts in a bid to protect themselves from ozone, e.g., opening the windows in the morning or resting at home during hot middays. However, it did not affect other routines such as the ways that hosts drove cars, as most participants already led an environmentally conscious lifestyle.

In comparison, regional effects of the project across the three testbeds were more varied. This is due to the contextual setting, the activities driven by environmental activists, the existence of established networks, and possibly additional factors not captured in the qualitative data. In Spain, where most relevant impacts at the regional level have been documented, the selected area was relatively

Table 3: Contextual setting and outcomes in the three testbeds.

\begin{tabular}{|c|c|c|c|}
\hline & Spain & Italy & Austria \\
\hline Testbed size & One closed valley & Three large regions & Two large regions \\
\hline Source of pollutant & $\begin{array}{l}\text { - defined } \\
\text { - large metropolitan area } \\
\text { (Barcelona) }\end{array}$ & $\begin{array}{l}\text { - undefined } \\
\text { - several urban and indus- } \\
\text { trial areas }\end{array}$ & $\begin{array}{l}\text { - undefined } \\
\text { - several urban and industrial } \\
\text { areas } \\
\text { · } \text { across country borders }\end{array}$ \\
\hline $\begin{array}{l}\text { Embedded in } \\
\text { environmental agency }\end{array}$ & $\begin{array}{l}\text { strong presence of en- } \\
\text { vironmental NGO } \\
\text { - long history of grass-roots } \\
\text { activities }\end{array}$ & $\begin{array}{l}\text { strong presence of envi- } \\
\text { ronmental NGO }\end{array}$ & $\begin{array}{l}\text { no local presence of environ- } \\
\text { mental NGO }\end{array}$ \\
\hline $\begin{array}{l}\text { Local activities accom- } \\
\text { panying the campaign }\end{array}$ & $\begin{array}{l}\text { workshops with politicians, } \\
\text { citizens, and other local NGOs } \\
\text { - local ozone exhibitions } \\
\text { - contributions in local TV and } \\
\text { newspaper } \\
\text { meetings with decisions makers } \\
\text { in Barcelona }\end{array}$ & $\begin{array}{l}\text { contributions in local TV } \\
\text { and newspaper }\end{array}$ & $\begin{array}{l}\text { - local ozone exhibitions } \\
\text { - contribution in local news- } \\
\text { paper }\end{array}$ \\
\hline $\begin{array}{l}\text { Previous knowledge } \\
\text { and awareness of hosts }\end{array}$ & - low in all three testbeds & & \\
\hline $\begin{array}{l}\text { Individual benefits of } \\
\text { hosts }\end{array}$ & $\begin{array}{l}\text { - increased knowledge } \\
\text { - personal awareness } \\
\text { - diffusion of information on the to }\end{array}$ & pic in local communities & \\
\hline Regional benefits & $\begin{array}{l}\text { raised awareness on ozone in } \\
\text { the whole valley } \\
\text { - ozone data are shown on TV and } \\
\text { the public place } \\
\text { - discussions with originators of } \\
\text { pollutants in Barcelona initiated } \\
\text { - the readiness of the } \\
\text { municipality to buy further } \\
\text { ozone measurement devices }\end{array}$ & $\begin{array}{l}\text { potential regional impact } \\
\text { not perceived } \\
\text { open issues raised like } \\
\text { more communication, } \\
\text { more devices in one } \\
\text { region, and increased } \\
\text { visibility of data on public } \\
\text { places and media }\end{array}$ & $\begin{array}{l}\text { potential impacts identified } \\
\text { and discussed } \\
\text { - open issues raised, e.g., more } \\
\text { public visibility of data (also } \\
\text { reference data), more devices } \\
\text { and communication } \\
\text { - the interest of one } \\
\text { municipality to further experi- } \\
\text { ment with low-cost devices }\end{array}$ \\
\hline
\end{tabular}


small, with all hosts located in one valley that is affected by the pollutants that come from the metropolitan area of Barcelona. This test region had a long tradition of environmental activism, and most hosts were participating in local environmental organisations; thus, they were embedded in a network of interested individuals. Additionally, the scientific embedding of the project was an important factor to create trust in the collected data, while local dissemination activities, such as meetings with local decision-makers, newspaper and television reports, and a public exhibition, contributed to wider awarenessraising. Beyond the affected region, political pressure was exerted towards political decision-makers in Barcelona, the main source of pollution, which strongly resonated with the project's participants. Within the testbed region, the associated public authorities felt the pressure from citizens and made ozone data available in public places and the local news, contributing to wide awareness of ozone amongst the local population.

Contrary to Spain, the hosts in Austria were not embedded in any local environmental agencies, thus there were neither established networks of interested citizens nor an established culture of environmental bottom-up activism. What was most obvious about this testbed were the main drivers of participation: Having very local air pollution data ("knowing the quality of the air that I breathe") and supporting an important societal topic. The involvement of scientists was not highlighted, rather, the independence of the project from any political parties' interests and its embedding outside party politics was most appreciated.

The call for more communication of the data towards the public to make "the invisible pollutant visible," as expressed by the hosts, is comparable to Spain. Because the network of official reference stations in Austria is quite large, participants expressed a call to the environmental agency to make their data visible. A need for more transparency and actual awareness-raising about the available official data and the issues related to ozone across the population was requested.

Additionally, a higher number of local events and dissemination activities, the link to other hosts, the embeddedness in a community - facilitated either by project representatives or other hosts - were required to foster attraction to the project. Regular and mutual communication about the effects and results were mentioned to stimulate a stronger impact on the whole region.

In addition to this enforced local communication, the affected regions also ask for measures that concretely fight against the polluters; then not only knowledge and awareness can be increased, but also the feeling that citizens and small municipalities can positively influence the ozone pollution.

When confronted with these requests in Austria, a public authority found CAPTOR interesting and a good way to show transparency and commitment to environmental issues. Also, the exchange with other communities, e.g., neighbouring municipalities, in this regard is suggested by the interviewee from the public authority, given that all communities do collect data and make them transparent. This requirement comes from the fact that smaller municipalities in the countryside are competing against each other for inhabitants. So, if one municipality shows high air pollution and the other does not, this could give people a feeling that there is a lower living standard in their town compared to others.

In Italy, the above-mentioned contextual setting was comparable to Austria, however the awareness for ozone across participants was lowest among the three cases. CAPTOR was starting from a base, where citizens in the testbed regions mainly thought that air pollution was an issue in urban, low-pressure areas in winter, but not a concern for rural areas in summer. Ozone was still an unknown pollutant.

Thus, effects were observed mainly on individual levels about an increased knowledge and awareness for ozone. Participation has been perceived as rewarding and promising, and the increasing knowledge perceived as important to protect the health of the participants' families and friends. Based on their experiences, the hosts see the need for more activities along with broad dissemination and communication using the measurement data to make the invisible problem visible to citizens in the affected region and to start dialogue and discussion between environmental organisations, political decision-makers, and media.

School collaborations were encouraged in all three testbeds to start educating the youngest members of society on this topic, and a high interest was also observed in workshops on how to build the measuring devices.

All volunteers in the three testbeds wanted to continue their participation and offered to take on more responsibilities and actions, given the necessary support structures. These included broad support in building, calibrating, and maintaining the devices; in communicating the topic to the broader public and to political decisionmakers; and to building alliances with other organisations to fight against the origins of pollutants.

While the study revealed interesting insights into the effects of the citizen-based air quality monitoring, it also shows how challenging this approach is. The project expected to achieve regional impacts in all three testbeds, but learned that this requires strong efforts in communication and community building (Van Brussel and Huyse 2018). In the case of ozone, the communication issue becomes highly complex as the source of pollutant is not identifiable nor addressable compared to other citizenbased air monitoring projects dealing with other pollutants (Hsu et al. 2017, Kloetzer et al. 2017, Van Brussel and Huyse 2018).

As air pollution is often a problem that disperses across large regions and traverses regional and national borders, it needs further research and consolidation of experiences from citizen-based air monitoring projects around the globe to answer questions like: Who will take leadership to drive citizen participation in air quality monitoring? Who will pay for the costs of maintaining the network of low-cost sensors and guarantee the high quality of data to support decision making? How can we fight pollution that affects the lives of citizens who are not the originators of the pollutant? If we can find answers to these questions, the effects of citizen science air sensing projects on those involved and their regions will be considerable. 
An additional suggestion for further research is to roll out a wider field study now that we have learned how lowcost measurement devices deliver reliable data (Ripoll et al. 2019). Having more hosts would allow quantitative investigations of drivers, barriers, and impacts, thus helping to gain a deeper understanding of how socio-demographic characteristics of participants, their engagement drivers, and the communication measures they take connect to the achieved impact on the individuals and their regions.

\section{Data Accessibility Statement}

Due to data privacy there is no access to the original interviews. To protect the privacy of participants, the research followed the ethical guidelines of the CAPTOR project. All data were anonymised before analysis.

\section{Note \\ ${ }^{1}$ Unique ID of interviewee.}

\section{Supplementary File}

The supplementary file for this article can be found as follows:

\section{- Supplemental File. Captor Host Interview Questions. DOI: https://doi.org/10.5334/cstp.245.s1}

\section{Acknowledgements}

We thank all of the citizens involved in the CAPTOR project who contributed their time and resources to this important research and provided us with rich feedback on their role as CAPTOR hosts. This work is part of the CAPTOR project, funded from the EU's Horizon 2020 Programme (grant agreement No. 688110).

\section{Competing Interests}

The authors have no competing interests to declare.

\section{References}

Ballard, HL, Dixon, CGH and Harris, EM. 2017. Youthfocused citizen science: Examining the role of environmental science learning and agency for conservation. Biological Conservation, 208: 65-75. DOI: https://doi. org/10.1016/j.biocon.2016.05.024

Barcelo-Ordinas, JM, Garcia-Vidal, J, Doudou, M, Rodrigo-Muñoz, S and Cerezo-Llavero, A. 2018. Calibrating low-cost air quality sensors using multiple arrays of sensors. IEEE Wireless Communications and Networking Conference (WCNC), 1-6. Barcelona. DOI: https://doi.org/10.1109/WCNC.2018.8377051

Castell, N, Dauge, FR, Schneider, P, Vogt, M, Lerner, U, Fishbain, B, Broday, D and Bartonova, A. 2017. Can commercial low-cost sensor platforms contribute to air quality monitoring and exposure estimates? Environment International, 99: 293-302. DOI: https:// doi.org/10.1016/j.envint.2016.12.007

Castell, N, Schneider, P, Grossberndt, S, Fredriksen, MF, Sousa-Santos, G, Vogt, $\mathbf{M}$ and Bartonova, A 2018. Localized real-time information on outdoor air quality at kindergartens in Oslo, Norway using low-cost sensor nodes. Environmental Research, 165(December
2016): 410-419. DOI: https://doi.org/10.1016/j. envres.2017.10.019

Castell, N, Viana, M, Minguillón, MC, Guerreiro, C and Querol, X. 2013. Real-world application of new sensor technologies for air quality monitoring. ETC/ACM Technical Paper, 16.

Conrad, CC and Hilchey, KG. 2011. A review of citizen science and community-based environmental monitoring: issues and opportunities. Environmental monitoring and assessment, 176(1-4): 273-291. DOI: https://doi.org/10.1007/s10661-010-1582-5

Cornwell, ML and Campbell, LM. 2012. Co-producing conservation and knowledge: Citizen-based sea turtle monitoring in North Carolina, USA. Social Studies of Science, 42(1): 101-120. DOI: https://doi. org/10.1177/0306312711430440

Danielsen, F, Burgess, ND and Balmford, A. 2005. Monitoring matters: Examining the potential of locally-based approaches. Biodiversity and Conservation, 14. DOI: https://doi.org/10.1007/ s10531-005-8375-0

Duvall, RM, Long, RW, Beaver, MR, Kronmiller, KG, Wheeler, ML and Szykman, JJ. 2016. Performance evaluation and community application of low-cost sensors for ozone and nitrogen dioxide. Sensors, 16(10): 1698. DOI: https://doi.org/10.3390/s16101698

EEA (European Environmental Agency). 2015. Air quality in Europe - 2015 report. Luxembourg, Europe.

EEA (European Environmental Agency). 2018. Air quality in Europe - 2018 report. Luxembourg, Europe.

Evans, C, Abrams, E, Reitsma, R, Roux, K, Salmonsen, L and Marra, P. 2005. The Neighborhood Nestwatch Program: Participant outcomes of a citizen-science ecological research project. Conservation Biology, 19: 589-594. DOI: https://doi.org/10.1111/j.15231739.2005.00s01.x

Francis, L and Stockwell, H. 2014. Science in the City: Monitoring air quality in the Barbican. [online access at https://mappingforchange.org.uk/wpcontent/uploads/2015/08/Barbican-Final-Reportdraft_12012015_edited.pdf].

Groulx, M, Brisbois, MC, Lemieux, CJ, Winegardner, A and Fishback, LA. 2017. A Role for Nature-Based Citizen Science in Promoting Individual and Collective Climate Change Action? A Systematic Review of Learning Outcomes. Science Communication, 39. DOI: https://doi.org/10.1177/1075547016688324

Haklay, M and Eleta, I. 2019. On the Front Line of Community-Led Air Quality Monitoring. In: Nieuwenhuijsen, $\mathrm{M}$ and Khreis, $\mathrm{H}$ (eds.), Integrating Human Health into Urban and Transport Planning, 563-580. Cham: Springer. DOI: https://doi. org/10.1007/978-3-319-74983-9_27

HEI (Health Effects Institute). 2018. State of Global Air 2018: Special Report. Boston, MA. [online access at https://www.stateofglobalair.org/sites/default/files/ soga-2018-report.pdf].

Hsu, Y-C, Dille, P, Cross, J, Dias, B, Sargent, R and Nourbakhsh,I.2017.Community-EmpoweredAirQuality Monitoring System. In: CHI 2017. Denver, CO, USA. 
[online access at http://arxiv.org/abs/1804.03293]. DOI: https://doi.org/10.1145/3025453.3025853

Johnson, MF, Hannah, C, Acton, L, Popovici, R, Karanth, KKand Weinthal, E. 2014. Network environmentalism: Citizen scientists as agents for environmental advocacy. Global Environmental Change, 29: 235-245. DOI: https://doi.org/10.1016/j.gloenvcha.2014.10.006

Kloetzer, L, Jennett, C, Francis, L and Haklay, M. 2017. Community Engagement Around Poor Air Quality in London:Citizen inquiryina citizen science "Mapping for Change" project. In: Citizen Inquiry, 42-62. Routledge. DOI: https://doi.org/10.4324/9781315458618-4

Kumar, P, Morawska, L, Martani, C, Biskos, G, Neophytou, M, Sabatino, S, Bell, M, Norford, L and Britter, R. 2015. The rise of low-cost sensing for managing air pollution in cities. Environ. Int., 75: 199-205. DOI: https://doi.org/10.1016/j.envint.2014.11.019

Macdonell, M, Raymond, M, Wyker, D, Finster, M, Chang, YS, Raymond, T, Temple, B and Scofield, M. 2013. Research and Development Highlights: Mobile Sensors and Applications. Washington, DC.

Mayring, P. 2010. Qualitative Inhaltsanalyse [Qualitative content analysis]. Qualitative Forschung: Ein Handbuch (Qualitative Research: A Handbook), 468-475. DOI: https://doi.org/10.1007/978-3-531-92052-8_42

McKinley, DC, Miller-Rushing, AJ, Ballard, HL, Bonney, R, Brown, H, Cook-Patton, S, et al. 2017. Citizen science can improve conservation science, natural resource management and environmental protection. Biological Conservation, 208: 15-28. DOI: https://doi. org/10.1016/j.biocon.2016.05.015

Muller, CL, Chapman, L, Johnston, S, Kidd, C, Illingworth, S, Foody, G, Overeem, A and Leigh, RR. 2015. Crowdsourcing for climate and atmospheric sciences: current status and future potential. International Journal of Climatology, 35(11): 3185-3203. DOI: https://doi.org/10.1002/joc.4210

Overdevest, C, Orr, $\mathbf{C H}$, Stepenuck, $\mathrm{K}$ and Huyck Orr, C 2004. Volunteer Stream Monitoring and Local Participation. Human Ecology, 11(2): 177-185.

Palmes, ED, Gunnison, AF, Di Mattio, J and Tomczyk, C. 1976. A Personal Sampler for Nitrogen Dioxide. Am Ind. Hyg. Assoc. J, 37: 570-577. DOI: https://doi. org/10.1080/0002889768507522
Ripoll, A, Viana, M, Padrosa, M, Querol, X, Minutolo, A, Hou, KM, Barcelo-Ordinas, JM and García-Vidal, J. 2019. Testing the performance of sensors for ozone pollution monitoring in a citizen science approach. Science of the Total Environment, 651: 1166-1179. DOI: https://doi.org/10.1016/j.scitotenv.2018.09.257

Stepenuck, KF and Green, LT. 2015. Individual-and community-level impacts of volunteer environmental monitoring: a synthesis of peer-reviewed literature. Ecology and Society, 20(3). DOI: https://doi. org/10.5751/ES-07329-200319

Van Brussel, S and Huyse, H. 2018. Citizen science on speed? Realising the triple objective of scientific rigour, policy influence and deep citizen engagement in a large-scale citizen science project on ambient air quality in Antwerp. Journal of Environmental Planning and Management, 0568: 1-18. DOI: https://doi.org/1 0.1080/09640568.2018.1428183

WHO (World Health Organization). 2016. Ambient Air Pollution: A Global Assessment of Exposure and Burden of Disease. Geneva: World Health Organization. [online access http://apps.who.int/iris/ bitstream/10665/250141/1/9789241511353-eng. pdf?ua=1]

Williams, R, Nash, D, Hagler, G, Benedict, K, Macgregor, IC, Seay, BA, Dye, T, et al. 2018. Peer Review and Supporting Literature Review of Air Sensor Technology Performance Targets. [online access https://www. epa.gov/sites/production/files/2018-10/documents/ peer_review_and_supporting_literature_review_of_ air_sensor_technology_performance_targets.pdf].

WMO (World Meteorological Organization). 2018. Low-cost sensors for the measurement of atmospheric composition: overview of topic and future applications. Geneva, Switzerland.

Zannella, C. 2017. Milano, cittadini 007 antismog: la mappa delle strade nere. Republica Milano, Maggio 2017 [online access: https://milano.repubblica.it/ cronaca/2017/05/18/news/milano_cittadini_007_ antismog_la_mappa_delle_strade_nere-165776489/ ?ref=search].

Zerbe, F and Wilderman, C. 2010. Monitoring Impacts of New Gas-Driling Technologies. The Volunteer Monitor, 21(1): 1-20.

\footnotetext{
How to cite this article: Schaefer, T, Kieslinger, B and Fabian, CM. 2020. Citizen-Based Air Quality Monitoring: The Impact on Individual Citizen Scientists and How to Leverage the Benefits to Affect Whole Regions. Citizen Science: Theory and Practice, 5(1): 6, pp. 1-12. DOl: https://doi.org/10.5334/cstp.245

Submitted: 15 April 2019 Accepted: 22 September 2019 Published: 03 March 2020

Copyright: (c) 2020 The Author(s). This is an open-access article distributed under the terms of the Creative Commons Attribution 4.0 International License (CC-BY 4.0), which permits unrestricted use, distribution, and reproduction in any medium, provided the original author and source are credited. See https://creativecommons.org/licenses/by/4.0/.
}

] $\mathrm{u}[\quad$ Citizen Science: Theory and Practice is a peer-reviewed open access journal published by Ubiquity Press. 